\title{
The use of narrative hermeneutical approach in the counselling of abortion patients within an African context
}

\author{
Author: \\ Elijah M. Baloyi ${ }^{1}$ \\ Affiliation: \\ ${ }^{1}$ Department of Practical \\ Theology, University of South \\ Africa, South Africa \\ Note: \\ This article is published in the \\ section Practical Theology \\ of the Society for Practical \\ Theology in South Africa. \\ Correspondence to: \\ Elijah Baloyi \\ Email: \\ baloye@unisa.ac.za \\ Postal address: \\ PO Box 392, UNISA 0003, \\ South Africa \\ Dates: \\ Received: 28 Sept. 2011 \\ Accepted: 24 Jan. 2012 \\ Published: 08 Aug. 2012 \\ How to cite this article: \\ Baloyi, E.M., 2012, 'The use \\ of narrative hermeneutical \\ approach in the counselling \\ of abortion patients \\ within an African context', \\ HTS Teologiese Studies/ \\ Theological Studies 68(2), \\ Art. \#1183, 7 pages. http:// \\ dx.doi.org/10.4102/hts. \\ v68i2.1183
}

C 2012. The Authors. Licensee: AOSIS OpenJournals. This work is licensed under the Creative Commons Attribution License.
Our country has celebrated democracy for more than a decade now, the democracy in which everyone enjoys all the basic human rights, including the right to an abortion. Public and private hospitals and some traditional healers are engaged in this act where some give preabortion and post-abortion counselling to their patients whilst others do not. It becomes a serious question of course to ask whether those patients who did not receive counselling, cope with life after the experienced trauma. By the looks of things it seems very clear that the people who commit abortion have a special need for help in order to cope with life thereafter. Another question now is whether the little counselling that they receive in the hospital before and after an abortion is satisfactory to their individual needs. That is why the author's focus is on the method or approach which the author thinks will better help the patients who find themselves in such a traumatic situation. The concentration is on the narrative-hermeneutical approach as one of the applicable approaches from the author's point of view.

\section{Introduction}

Abortion has become a norm of life in our society. Although the government passed the law on it as a result of which in some situations (for instance when it threatens the life of the mother) it may be allowed, yet sometimes it is committed without any specific reason. Abortion in itself will always have unintended negative effects on the life of the women who had it performed and people close to her. It is a painful situation to realise that when it is performed in hospitals where professionals can help the person concerned before and after the abortion or intervention, other women opt to consult African traditional doctors or healers who in some cases are not professionally trained to help with counselling. It goes without saying that without proper counselling before and after, the person under question is not going to live the same life as she lived before.

Therefore for the sake of the post-abortion experience, this article is aimed at trying to argue that the hermeneutic narrative is one of the counselling methods that can play a significant role in helping the victims of abortion. This research is not intended to do away or rule out the other counselling methods which are performed by nurses, social workers and other professionals in the clinics and hospitals, but it is intended to address the spiritual side of counselling. It is advisable to remember that even though nurses and social workers are professionals in their respective fields, some are not Christians and hence this Christian approach can add value to the counselees who believe in God. As a pastoral caregiver, the author realised the need for this type of study so as to help patients as well as fellow pastoral caregivers since it is not easy to watch the situation where, in the first place young girls are being traumatised by their post-abortion problems whilst there is something that can be done in order to help the situation. Having taken note of above mentioned the information, the researcher is aware that some women receive preabortion and post-abortion counselling, whilst others do not receive any therapeutic counselling and go on with their lives as if nothing had happened - this is where the problems arise.

\section{Objective and design}

Abortion as a legal Act has been available in our country for some years now; at the time it was promulgated some people tried to object against it and others tried to support it. Yet, despite this Act many teenagers still turn to back street abortionists rather than legal facilities to end unwanted pregnancies. The Sowetan newspaper dated 04 August 2009 published an article entitled: 'Unsafe abortions rife among teens.' In this article (Serithi \& Ndlhovu 2009) the authors said:

A health professional who declined to be named said back-door abortions have harmed many girls. Some die and others are unable to conceive again because their wombs are damaged. In desperate attempts, women go to traditional healers or self-medicate with over-the-counter medicine such as laxatives or household products. Others have had electrical wires, with the copper wires exposed, inserted inside their private parts. Some use a crochet needle that hooks onto the uterus hoping to terminate the pregnancy. (p. 4) 
This is a real story that depicts a situation in which there exists a lack of pre-abortion as well as post-abortion counselling. Many people have died and others are still to die from the consequences of an abortion, but the questions are: 'Should the church fold its hands and do nothing about it; is the counselling offered by the hospitals satisfactory to our people; does it cater for every individual problem; can the church through its pastors extend its helping hand to what the government is doing?'

But then how does the church offer its pastoral helping hand to the victims? According to the author, one systematic way of helping people must come from the pastors whose other challenge is to check and look for ways on how to improve the existing counselling methods which take place in hospitals as well as putting counselling centres in place for those patients who could not get counselling due to the fact that their abortion was performed where there was no counselling available at all. Therefore, for this study our argument is not about the legalisation of abortion, but it is about finding a different way in which pastoral caregivers can help patients who have undergone an abortion, to cope with their trauma. I will use the concept 'patients' to refer to women who had abortions performed. The author comes from the place where abortions are being performed and conducted both professionally by the hospital and medical practitioners and also unprofessionally by witchdoctors and traditional healers.

It is also relevant to indicate why the author chose the narrative hermeneutical approach to be the best as well as useful amongst the other pastoral approaches. According to the author's own view, the fact that the patients who are the objects of this article are from different cultural backgrounds makes it important to attend to their problems differently and individually. For instance there are Christians, traditional healers, Shangaans, Vendas and people from Mozambique in the area. Each of these people has her own belief, culture and religion. Therefore, it was only after the author made a study of narratives, that the author realised that the narrative approach could accommodate each one of the people and groups. According to Gerkin (1997:112) the narrative approach would be able to give participants an opportunity to tell narratives within the context of their own peculiar language and cultural context.

It is not easy to know what the motives for the performance of the abortion, as well as the after effects of same are, neither is it easy to assess what patients have been through, without listening to their stories as they narrate them. The reasons for the decision to have an abortion for instance, varies from person to person, and this fact determines the choice of the approach most suitable for such patients. That is what Gerkin means when he said that the role of the ascribed pastors or counsellors is to be ready to attentively listen to the patients (Gerkin 1986:45).

According to Weingarten (1998:3) the issue of respect is also important in counselling. Lack of respect closes the door for counselling. That is why he went on to say: 'Respect includes respect not only for different points of view, but also cultures and language metaphors' (Weingarten 1998:4).

Some patients do not want to take the responsibility for their own lives, but prefer the pastor or counsellor to be their expert. Therefore with the narrative approach every one will get her turn to explain her own feelings about the postabortion effects. It also should not be neglected to mention that social realities and concerns are involved here, so the socially constructed and constituted stories can be organised and maintained through narrative. For this reason the narrative hermeneutical approach is of vital importance in this type of counselling.

\section{Narrative hermeneutical approach explained}

According to Stroup (1991:424) narrative is a theme that emerges not just in a few theological communities but crosses most denominational boundaries. Practically, every theological discipline has seen some proposal for the use of narrative as a means for rethinking the nature, method, and tasks of that discipline. For several years workgroups for narrative theology and hermeneutics have been part of the annual meeting of the American Academy of religion. Wisse (2009:1) is of the opinion that narrative theology provides the building blocks for systematic and for biblical theology.

The Encarta World English Dictionary (2009) defines a narrative as an art of the process of telling a story or giving an account of something. In other words it means a story or an account of a sequence of events in the order in which they happened. The Wikipedia defines narrative a construct created in constructive format (written, spoken, poetry, prose, images, song etc.) that describes a sequence of fictional or non-fictional events. Therefore stories are also ubiquitous components of human communication, used as parables and examples to illustrate points. Whilst summarising the definition of a narrative Gerkin (1984:26) says: 'Pastoral counsellors are more than anything else, listeners, to and interpreters of stories. A person seeks out a pastoral counsellor because they need someone to listen to their story.'

Wimberly (1994) agrees with Gerkin when he says:

Pastoral counselling begins with presenting a problem that individuals bring to pastoral counselling. The problem unfolds like a story, a dramatic fashion one scene at a time. Consequently I spent the early stages of counselling attending to the presenting problem and the story that surrounds the problem. (p. 21)

That is why in the narrative approach and relating a story before interpretation, becomes a second skill in establishing relationship with the counselee (Howard 1993:40).

According to Belzen (1997:173) the epistemological question: 'How do we know and what account can be trusted?' 
contributes and influences the development of a paradigm that we call narrative approach. Besides, a number of authors have now been influential in contributing to a narrative approach to understand human behaviour as a part of psychological research. In short, when we speak of a narrative, we wish to emphasise that when people account for themselves, or when they describe their experience, they often do so in story form. It is the belief of the researcher that the narrative approach applied to a person's belief, skills, principles and knowledge may help that particular person towards the possible solution of her problem. This is completely in agreement with what Morgan (2000:1) means when she says that narrative centres people as experts of their own lives.

A counsellor must be ready to listen and interpret the stories of patients in order to help them cope with life after they have experienced problems. That is why the author is fully in support of Gerkin when he articulates that pastoral care is located in the centre of the dialogue between the Christian story and life stories (1997:112). By this he means that the counsellor and counselee must have a dialogue through which the problems of the latter can be communicated to the former. This view is emphasised by White and Epston (1990:83) when they see narrative therapy as: 'Providing person's lived experience and encouraging a perception of the world through this live experience.'

In other words, listening, hearing and interpreting stories from clients form the basis of the narrative approach. That is why Gerkin (1986:32) asked whether pastors could interpret without hearing. This means that pastors who are able to listen to stories, will then be able to interpret and translate them.

\section{The impact that abortion have on its patients}

In this article the author's concept 'abortion patient' refers to women and daughters who voluntarily discontinued or terminated their pregnancies. We can also call them victims or abortion sufferers, but for this study, the author prefers 'patients' as was stated earlier. Every women who underwent an abortion will always have a unique and different background (as mentioned above) which might lead to different experiences as well as different consequences of the abortion. Abortion is not just a simple medical procedure. For many women it is a life-changing event with significant physical, emotional and spiritual consequences. For this reason most women who struggle after the abortion say that they wish they had been told all about its consequences before they decided to undergo the procedure.

Although the organisation which supports abortion in the United States of America (USA) say that abortion does not hurt because: 'You will not feel, see or remember anything about it thereafter' (Choices Women's Medical Center), Pavone's research indicates that abortion does not help, but it hurts. During one of his post-abortion healing seminar Frank Pavone (2011) argues:

The idea that abortion solves problems is a deception and illusion. The reality is that it solves nothing and brings a host of problems of its own. Nobody knows exactly how many women suffer the after effects of abortion. (n.p.)

In supporting the above argument, the author will shortly list the dangers that are caused by abortion that are also shared by other writers in the same field. The first one is the inflammation of the cervix which is very common. It may sound harmless, but the results of this side effect tend to be very severe and it can also lead to inflammation of the pelvis which can eventually permanently damage the patient's pelvis. It can also lead to cervical cancer which killed about 4021 women in the USA (National Center for Chronic Disease Prevention and Health Promotion 2011) in 2007. Anaesthesia complications caused by abortion resulted in 486 deaths in the US. Other emotional and psychological effects are: eating disorders, relationship problems, guilt, depression, flashbacks of abortions, suicidal thoughts, sexual dysfunction, alcohol and drugs abuse (Elliot Institute 2011).

Infertility is another after-effect of abortion, hence abortion is held accountable for at least $30 \%$ of women who are experiencing problems with infertility in the United States today. Other complications are premature births, miscarriages, and even infant deaths (Beth \& Robert 2011:86-91).

David Reardon (2012) of the Elliot Institute lists the following as woman's psychological reactions reported after an abortion according to his research:

- feeling of guilt and fear of punishment from God

- preoccupation with thoughts of the child they could have had

- hatred for men who impregnated them

- ending relationship with the man who impregnated them after abortion

- feeling of anxiety

- promiscuous

- self-destructive

- non-functioning well at home and work

- abortion threatens women's self esteem

- abortion trauma and child abuse.

On the other hand Warren Hern (1981:28) in his article entitled 'Complications you can have with your abortion', indicated the other effects of abortion on the woman as:

- bladder injury

- bowel injury

- breast cancer

- ectopic (tubal) pregnancy

- haemorrhage: $1 \%-14 \%$ of women require blood transfusions due to bleeding during abortion

- sterility: one out of twenty women became sterile unaware after abortion according to his research.

Herm (1980:28) went on to argue that it is less likely for such women after abortion to have normal births in future. The information given about what the consequences of abortion 
are, clearly indicates the necessity for counselling that must be offered to the patients in order for them to heal from possible trauma that can be caused by the consequences. It would be irresponsible for the church to not provide counselling for these people in order to help them to bring their lives back on track. Without undermining the hospital services and counselling as well as the nursing care, it is the personal perception and opinion of the author that the church, through its pastoral counsellors may shoulder the responsibility.

\section{The reasons (and the need for narrative) for abortion vary from person to person}

As far as abortion is concerned, the reasons vary from one person to the next. Therefore this makes it important that every patient's situation and circumstances should be taken into consideration. Without negating or taking one reason for granted, the study will try to discover most of the reasons for why people want to abort their babies. According to the research conducted by Torre-Bueno of University Health Systems of Eastern Carolina the first reason for women to abort babies is the following:

\section{Birth control (contraceptive) failure}

The American research indicates that over half of all women who have an abortion used a contraceptive method during the month they became pregnant. Akinrinola, Susheela and Taylor (1998:117) have this to say: 'Contraceptive use does not necessarily provide complete protection against pregnancy, each method can fail, even when it is used properly.'

This reason does not only apply to America, but to many women even in South Africa, particularly in the author's research area, cited this as one of the reasons for falling pregnant. The problem is that because of little education, many women who use contraceptives do not first consult medical practitioners for advice, and thus they may only find out afterwards that the method they used does not suit them. That is why the Religious Tolerance research indicates that $71 \%$ out of those who committed abortions did not know that they were pregnant (Torres \& Forrest 1988).

\section{Inability to care for the child}

This problem is the most common, if not general for most of the women and girls who opt for an abortion. The Malamulele area in Limpopo is one of the places most affected by unemployment and poverty. With the large number of legal and illegal immigrants from both Mozambique and Zimbabwe for reasons well known in our country, these areas become over populated to the extent that many people just live by the mercy of the Lord. Some people lack clothes others do not have a shelter or food.

The large number of street children in our country - many of whose parents have abandoned them - proves that people are financially unable to take care of them. But these factors are not enough to stop the natural desire for man to marry and bear children. Therefore most young girls realise that, after bearing one or two children, the issue of supporting children is not easy. Social grants that are provided by the government are exceptionally small to enable a mother to take care of the child from birth until his or her tertiary studies. Whilst the National Right to Life states that $23 \%$ of abortions are caused by 'she can't afford to have a baby', the Holysmoke's research indicates the figure as being 21\% for the same reason (Torres \& Forest 1988:169).

This realisation does not stop women from sexual relationships, which are sometimes gone into without any family planning or birth control. Only when she is pregnant does the realisation of the possible problems ahead enter her mind. This is one of the explanations that the researcher was given when visiting some hospital staff members for this study. According to Guttmacher, Anne Nicol Gaylor's research for 'Freedom From Religion Foundation' finds this one of the most common and devastating factors that caused many people, especially young girls, to commit abortion in America (Guttmacher 1987:168)

The Healthwise Medical Writer (Medew 2009) refers to the unplanned pregnancy when stating that:

In the US, about 6 million women become pregnant per year, half of which are unintended for, especially with the reason that the mother cannot afford to support the child. (p. 1)

Julia Medew's report also supports this as one of the reasons when she says: 'Financial, relationships or medical reasons together accounted for 19\% of abortion cases' (Medew 2009:1).

The pastoral counsellor will need to work very hard to uncover this information, since some people are too shy to speak about it. It will need some kind of relationship and friendship with the patient, because they feel ashamed to discuss this dilemma with strangers. It should be known that some cultures simply regard anyone (pastors included) as a stranger and do not easily take them into their confidence. Stories like these can be traced and made known if the pastor is a good narrator who gives time to the patient whilst he or she patiently relates the story and he does listen to these stories.

\section{Fear to tell parents}

This is one of the most dangerous reasons for an abortion, since it can also lead to suicide. There are cases where girls tried to perform an abortion without the parents knowing that they were pregnant and, after failing to abort, they decided to commit suicide. The research conducted by Torress and Forrest (1988) of the Holysmoke Institute, girls corroborated the reason that the author found during his research. This reason articulates that most young mostly teenagers are forced to abort their pregnancies because of fear that their parents will get to know about it. According to traditions, many parents do not expect their young children to have babies, thus it is frightening for girls who fall pregnant in 
their teen years since that will jeopardise their education and future. Some parents find it very difficult to accept the mistakes made by their children to the extent that children opt for a hidden abortion in fear of their parents.

The tradition initially forced parents to expel their pregnant children from homes and force them into an unprepared marriage since they could not allow their daughters to have children outside the marriage. Although some young girls are now becoming used to telling their parents that they are pregnant, it was initially seen as a taboo to the clan and to the entire family. Some are still holding onto that tradition and they therefore plan secret abortions about which the parents may later discover or not discover the truth at all. Even though culture and tradition are being revised and changing, the fact that young girls, who are still under the guidance and supervision of their parents, fall pregnant is still disapproved of traditionally and religiously.

\section{Fear of not getting married after abortion}

Most traditional men do not intend to marry someone who already has a child. Therefore if an unplanned pregnancy occurs, the girl will arrange an abortion, as a child could later become a stumbling block if she might want to marry someone else. It is well known in the African tradition, that a marriage with a girl who already has a child, is not approved or condoned, in fact men must marry someone who is still a virgin. When a girl enters a marriage with a child, this puts pressure on the marriage. For that reason, many young girls do not feel comfortable if they find that they are pregnant, as that situation will jeopardise their chances of getting married in future.

\section{Interference with education and career plans}

A teenager of 16 years in 2006 (Tshepang Mashego) from Soshanguve in Tshwane told her own personal story to the Sowetan (2009) journalist saying:

I was 16 when I tried to end my six-week pregnancy. At my age I succumbed to pressure from friends and peers who were at school by then. Because of wanting to continue with my studies I went to a local community clinic where I waited for hours in long queues for attention. The nurses were so rude that I opted to take an advice of the newspaper advert about someone who offered abortion services. (p. 8)

This story is a clear indication that abortions are performed because they wreck education and future plans.

According to Finer et al. (2005:112) 74\% of those who responded to structured interviews about the foetus they aborted, communicated that they did that because their education is disturbed, hence their career would end up in jeopardy. According to Guttmacher (2012), quoting Lawrance et al. fully agree that continuing with education is the reason given by most young people who wanted an abortion. A large number of young girls who fall pregnant during the course of their studies use this as their reason for an abortion. There are parents who planned and invested large amounts of money for the studies of their children. This puts more pressure on the girl who was promised to go and study at the university or elsewhere, if she realises that she is pregnant and this fact may become a hindrance for her to study further. Some parents, who are willing to take the education of their daughters further, become frustrated when these daughters fall pregnant and they will try to encourage and persuade their daughters to end such a pregnancy by abortion.

\section{Healing ortherpeutic ways of dealing with abortion Listening to stories of patients}

The importance of listening received much attention from Boyd (1996:28) who says that to listen with agape-love requires one to counsel with a non-judgemental attitude, readiness to help tolerance, acceptance and unconditional positive regard.

The listening skills of the counsellor regarding the tales and stories that are related by the patients are of vital importance in this regard. As every person has her own personal reason why she opted for an abortion, this means that she will need somebody to carefully listen to her in order for her to tell and explain when and why she made the decision to abort her foetus. This process will obviously need time; this will include and involve the family background as well as her own, so that the counsellor can understand what took place. Since abortion in itself is a sin, it goes without saying that like any other sin, it brings with it its own problems according to Fagerstrom (1996:23). This spiritual fragmentation between the patient and God cannot be repaired without the assistance of a counsellor who is ready to hear out every detail of the story that the patient will try to relate and only then can he or she give the relevant assistance. On listening, Fagerstrom (1996) has this to say:

Sometimes counsellors need to be reminded of the importance of those who come for help. The key thing is to remember to listen to their pain, their exhaustion, their shuttered dreams, their sense of loss and lifelessness and use the skills of active listening to help them see that you understand. (p. 214)

The author is of the opinion that since each woman will have her own reason for the abortion, the better part of counselling should be dominated by listening. This will help the counsellor to know exactly how to help each patient according to her own circumstances and situation.

If pastoral counselling, according to Gerkin (1997:118), has much to do with the reinterpretation of the tradition that shapes Christian identity, as that tradition is brought into dialogical relationship, there is no way one can interpret without having listened first to the stories about the situation which he or she has to deal with. That is why Gerkin (1997) said:

Pastoral care of a congregation of God's people involves the construction of a particular, context-relevant theological awareness on the part of both pastor and people. The rich descriptions of life give way to flat or monographic descriptions, descriptions that are generative of thin conclusions. (p. 121) 
White (1997:17) said that in the formalisation of knowledge, persons become differently acknowledged. A class of knowledge which is unwilling or modest, for instance where particular and local knowledge is used, is very different to the class of knowledge which is universal or global.

\section{The process of mediation and interpretation}

The subjective interpretation of facts according to Hansen (2003:2) is one of the important parts of narrative approach. It is both an approach and methodology, providing mediators with a way to incorporate stories into the very fabric of mediation. In other words, for a counsellor to be able to help someone who is stressed by the post-abortion experience, it is necessary that the story of such an individual be modified and developed in order to interpret it carefully (Cobb 1994:53). That is why White (1997) says:

Private and collective lives, properly re-remembered, are interpretive. Full or thick description is such an analysis. This involves finding linkages between the groups' shared value beliefs and symbols, and specific historical events. Particularities are subsumed and equated with grander themes, seen as exemplifying ultimate concerns. (p. 16)

This will indeed involve the language through which the patient will explain her story and which the listener must understand. Therefore the very naming and giving meaning to a word that will lead to a certain perception of the concept, gives language an important role to play (Hansen 2003:3).

\section{Patients should become experts of their own lives}

In narrative approach counsellors therapeutically help to examine, evaluate and change the patient's relationship to a problem by acting as investigative reporter who is not at the centre of the investigation, but is nonetheless influential. According to White (2005:15) the outsider in the narrative is asked in what ways they may feel a shift in how they experience themselves from when they first entered the room. In this way the counsellor does not want to become an expert of one's life, but the patient is helped to help him or herself. Just like in the case of abortion, the patient is the person with all the pain and she can experience the changes that are taking place in her life through the therapeutical process. Those who have committed an abortion must be helped to understand that they have many skills, competencies, beliefs, values, commitment and abilities that will assist them to reduce the influence of the problems in their own lives (Morgan 2000:2).

In other words the patients should externalise their problems. Externalisation is an approach to therapy that encourages persons to objectify and at times, personify the problems that they experience as oppressive (White \& Epston 1990:38). This is one way of establishing a context where a person experiences himself or herself as separate from the problem and the problem no longer speaks to them of their identity or the truth about who they are. Putting the patient at the centre of the discussion about their own lives will help them to therapeutically heal themselves. In that way the narrative approach takes a bigger picture than the other approaches. The message that the approach is trying to bring is that: 'We are in this together' (Swart 2003:28). This message encourages the patient to cope with the counselling sessions which will in the end be helpful to her.

\section{Conclusion}

There are of course many methods that can be used to counsel the patients on abortion, but the method of narrative hermeneutics can be also of good use. It gives a patient more time to become her own helper. It does not allow the counsellor to prescribe or command what should be done for the healing, but the patient has much to contribute through telling her story. The other important thing about this approach is that it can individualise every patient's problem and avoid unnecessary generalisations for the abortion patient. It also takes into consideration the context in which the patient finds herself, which helps to differentiate the problems between the different patients. In fact in the end there cannot be one method to help all, because every situation and every story will determine the method to be used to achieve the desired result for a particular problem.

\section{Acknowledgement Competing interests}

The author declares that he has no financial or personal relationship(s) which may have inappropriately influenced him in writing this article.

\section{References}

Akinrinola, B., Susheela, S. \& Taylor, H., 1998, 'Reasons why women have induced abortions: Evidence from 27 countries', Journal of Medical Ethics 24(3), 117-127.

Beth, A.B. \& Robert, J.S., 2011, 'Prenatal alcohol exposure and miscarriage, stillbirth, preterm delivery and sudden infant death syndrome', Journal of the National Institute on Alcohol Abuse and Alcoholism 34(1), 86-91.

Belzen, J.A. (ed.), 1997, Hermeneutical approaches in psychology of religion, Rodopi, Amsterdam.

Boyd, G.E., 1996, The A.R.T. of agape-listening: The miracle of mutuality, Agape House Press, Sugar Land, TX.

Cobb, S., 1994, Narrative perspective on mediation: Toward the materialization of the story telling metaphor, Sage Publications, San Diego, CA.

Elliot Institute, Abortion risks: A list of major psychological complications related to abortions, viewed on 19 April 2012, from http://afterabortion.org

Encarta World English Dictionary, 2009, s.v. Narrative, Microsoft Corporation, Redmond, WA.

Fagerstrom, G.L., 1996, Counseling single adults, Baker, Grand Rapids, MI.

Gerkin, C.V., 1984, The living human document, Abingdon Press, Nashville, TN.

Gerkin, C.V., 1986, Widenning the horizons: Pastoral responses to a fragmented society, Westminister, Philadelphia, PA.

Gerkin, C.V., 1997, An introduction to pastoral care, Abingdon Press, Nashville, TN.

Guttmacher, A., 1987, A survey of 1900 Abortion patients, Guttmacher Institute, Los Angeles, CA.

Guttmacher, A., 2012, Facts on Unintended Pregnancy in the United States, viewed on January 2012, from http://www.guttmacher.org

Hansen, T., 2003, The narrative approach to mediation, viewed on 23 March 2012, from http://www.adr.gov/approach.mediation

Hern, W., 1981, 'Arguments of abortionists', Time Magazine, p. 28.

Howard, W.S., 1993, Creative pastoral care and counselling series, Fortress Press, Minneapolis, MN.

Finer, L.B., Frohwirth, L.F., Dauphinee, L.A., Singh, S. \& Moore, A.M., 2005 'Reasons U.S. Women Have Abortions: Quantitative and Qualitative Perspectives', Perspectives on Sexual and Reproductive Health 37(3), 110-118.

Medew, J., 2009, Report reveals abortion reasons, viewed on 23 March 2012, from http://www.theage.com.au 
Morgan, A., 2000, What is narrative therapy?, Dulwich Centre Publications, Adelaide. National Center for Chronic Disease Prevention and Health Promotion, 2011, Cervical cancer rates by race and ethnicity, viewed n.d., from http://www.cdc.gov/ Features/dsCervicalCancer

Pavone, F., 2011, Frank Pavone and Dr Alveda King announce support for congressman Frank's Prenatal Nondiscrimination nation Act, viewed 06 December 2011, from http://www.priestforlife.ors

Reardon, D., 2012, Healing After Abortion: Interview with David Reardon of the Elliot Institute, viewed 10 April 2012, from http://www.priestforlife.org

Serithi, R. \& Ndlhovu, T., 2009, 'Unsafe abortions rife among teens', Sowetan, 04 August, p. 4.

Stroup, G., 1991, 'Theology of narrative or narrative theology? A response to why narrative?', Practical Theology Today 47(4), 424-432.

Swart, C., 2003, 'Caring with women married to Dutch Reformed Clergymen Narratives of pain, survival and hope', MA Research, Department of Practical Theology, Unisa.
Torres, A. \& Forrest, J.D., 1988, 'Reasons why many women chose to have abortion, Family Planning Perspectives', Bimonthly Journal of the Alan Guttmacher Institute 20(4), 169-176.

Weingarten, K., 1998, Stretching to meet what's given: Opportunities for a spiritual practice, Froma Walsh Spiritual Resources in Family Therapy, New York, viewed on 23 March 2012, from http://www.witnessingproject.org

White, M., 1997, Narratives of therapists' life, Dulwich Centre Publications, Adelaide. White, M., 2005, Narrative practice and exotic lives: Resurrecting diversity in everyday life, Dulwich Centre Publications, Adelaide.

White, M. \& Epston, D., 1990, Narrative means to the therapeutic Ends, Dulwich Centre Publications, Adelaide.

Wikipedia, s.v., Narrative, viewed on 10 April 2012, from http://www.wikipedia.org Wimberly, P.W., 1994, Using scripture in pastoral counselling, Abingdon Press, Nashville, TN.

Wisse, M., 2009, Narrative theology and the use of the Bible in systematic theology, University of Heidelberg, Heidelberg. 